Research Article

\title{
Construction of Rural Cultural Service System Based on Mobile Information System
}

\author{
Xingfu Qu ${ }^{1}$ and Fanqi Zhu $\mathbb{D}^{2}$ \\ ${ }^{1}$ School of Art and Design, Guangdong University of Technology, Guangzhou 510060, Guangdong, China \\ ${ }^{2}$ College of Music and Dance, Guangzhou University, Guangzhou 510006, Guangdong, China \\ Correspondence should be addressed to Fanqi Zhu; zhufanqi@gzhu.edu.cn
}

Received 12 June 2021; Revised 13 July 2021; Accepted 29 July 2021; Published 3 September 2021

Academic Editor: Sang-Bing Tsai

Copyright (c) 2021 Xingfu Qu and Fanqi Zhu. This is an open access article distributed under the Creative Commons Attribution License, which permits unrestricted use, distribution, and reproduction in any medium, provided the original work is properly cited.

\begin{abstract}
At present, the development of rural culture is gradually rising. Under the promotion of the sense of freedom and democracy, mobile information system also plays an important role in rural cultural services. This paper uses edge algorithm to build mobile information system, combined with rural cultural service elements, to carry out information construction for the people's needs of tourism, information, and belief culture in the development of rural China. In this paper, with the county or township service projects as the research content and 200 residents of a community as the research object, using the way of questionnaire to survey the respondents, online questionnaire feedback results received 186 , the effective rate of $93 \%$. This paper investigates the project support of mobile information system for rural cultural services and the satisfaction degree of residents' demand for various cultural resources. Research shows that the rural cultural service system based on mobile information system can improve the scope of cultural services. From the survey results, $65.53 \%$ of the people think that the cultural service system can reduce people's dependence on special cultural services, so as to obtain resources from the diversified information service system. $35.63 \%$ of the people said that the efficiency of cultural service system could be improved by more than $50 \%$ compared to that of offline cultural service. Others said that the rural cultural service system could basically meet their living needs. Therefore, whether from the perspective of cultural service or information system, the current rural cultural service mode and service process need to be constructed from the perspective of cultural service supply system reform.
\end{abstract}

\section{Introduction}

The influence of information technology system on culture is not determined by direct technology but by the changes of cognition, behavior, organization, and political culture which are widely connected into the information system. This emphasizes the importance of changing the perceptions and behaviors of service recipients and service providers and facilitates innovation in the processes and service modes of an organization and the political and cultural environment it faces.

In terms of cultural communication, Wang et al. study information system technology, mapping the real location of information to a virtual location for data submission, but there are some unreasonable situations in the information system, which lead to lower privacy [1]. Based on spatial generalization technology, Kiec et al. propose a location privacy protection method based on granularity, which adaptively generalizes information location to different granularity spaces [2]. Remneva proposes a location $k$-anonymity method, in which the location of any information is indistinguishable from that of other $k-1$ information [3]. However, the mobility of information nodes will lead to the change of the anonymous area, which makes the area of anonymous area too small to meet the privacy or too large to reduce the location accuracy. Lin et al. propose a centralized differential privacy protection technology based on the amount of area coverage, which constructs a differential privacy protection model based on the amount of information in 
a unit area to protect the personal position in urban population flow data [4].

In terms of data perception of people's cultural information, Manzur et al. define a density constraint to calculate the global sensitivity of the location information of the overall perception information, construct a Laplace noise component satisfying the differential privacy, and perform differential privacy protection on the location information of the overall perception data [5]. Sharma et al. design a mobile group intelligence perception system architecture under the protection of data privacy and realize the functions of node authorization verification, node anonymous submission of data, data privacy verification, and information anonymous incentive distribution by using the cooperation among multiple functional entities [6]. Livinus et al. construct multidimensional group intelligence perception data satisfying LDP based on Copula function [7]. Sun and Peng proposed the loPub method, built a multidimensional local differential privacy perturbation mechanism, solved the node privacy protection mechanism under multiattributes, and used statistical computation methods to single-attribute from multidimensional joints. The edge distribution is calculated [8]. Liu et al. proposed PrivKV method, which is a privacy publishing mechanism for key value data. The data of key attribute and value attribute are disturbed by LDP respectively, and the data statistics algorithm is provided to calculate the frequency of key and the mean value of values from the data that is privatized [9].

This paper uses edge algorithm to construct a mobile information system and constructs a rural cultural service system based on the mobile information system. Combining with the elements of rural cultural services, the development of China's rural people's needs for tourism, information, and belief culture will be informatized. This article uses county or township service projects as the research content and 200 cases of residents of a certain community as the research object. The respondents are surveyed by means of questionnaires. The online questionnaire results received 186 responses, an efficiency of $93 \%$. The survey content of this paper is the project support of the mobile information system for rural cultural services and the degree of satisfaction of the residents' needs for various cultural resources.

\section{Cultural Social Policy and Marginal Algorithm of Cultural Services}

2.1. Social Policy of Cultural Services. To enhance the affinity and ease of use of cultural service application by "service cocreation," and to achieve service cocreation and value cocreation by introducing service users into the field of public service production, is a worldwide public service innovation trend and an inevitable choice to comply with the trend of democratization [10]. In the process of rural cultural public service transformation, it is of great significance to guide the orderly participation of service users. Through the active participation of service users, the affinity and ease of use of services can be effectively improved, so as to avoid or reduce the adverse impact of "digital divide" on the digital poor groups [11]. Specifically, three measures can be taken to increase the cocreation depth of cultural public services.

First, establish the core value of "service cocreation". In theory, the transformation of cultural public services can achieve multiple values. The first is the political value of public service organizations, that is, through high-quality cultural services to improve people's satisfaction and sense of acquisition and ultimately enhance people's political trust [12]. The second is the cost value of service objects; that is, through open and transparent service procedures and shared cultural service design, users' use costs can be reduced, and even the public can enjoy high-quality public services free of charge [13]. The third is the experience value of the service object, that is, to improve the service experience value of the service object through the service object's independent selection and participation, customized service, instant delivery, automation, and other ways; The fourth is the value of service platform, that is, to create network effect through cultural ecosystem, cultural data opening, and resource sharing and increase the service value of service objects on the cultural service platform [14].

The abovementioned service value can only be realized in the service design, production, supply, and evaluation stages on the premise of full participation of service objects. The premise is that service planners and suppliers should have corresponding awareness and habits and regard citizen participation as an effective channel to promote service quality, instead of regarding citizen participation and opinions as "ungrateful" and "disobedient" [15]. In terms of service application software development, it is necessary to change the mode of collaborative development between service software designers and service providers into a service software development mode in which typical service users and digital poor, service providers, and software designers participate in the whole service design and service supply process including planning, construction, and operation [16]. Successful participatory public service design projects require the participation of appropriate and representative service users. In the process of designing cultural change and providing local public services, we need to select poorly educated older people and women as representatives to participate in the process of service design and service supply. Only in this way can their needs be better met, improving the quality of public service supply [17]. To guide the cultural transformation of business and other organizations, to promote the formation of digital ecological community, and to achieve the expected effect of the cultural transformation of public services, two preconditions of e-culture are needed: one is the cultural transformation of cultural partners, and the other is the high cultural literacy of service objects [18]. Only in this way can a close cultural connection be established between culture and the people, and between culture and other organizations, so that the supply of cultural public services can create the greatest value. The digital literacy promotion strategy of service objects has been discussed in detail in the previous paper, and this paper will focus on the issue of cultural partners. Compared with the eastern developed areas, the proportion of traditional enterprises with relatively low technical level 
and relatively poor digital ability in rural business and other organizations in China is higher, and there are big defects in cultural transformation willingness, transformation ability, and antirisk ability, which makes it difficult to provide sufficient technical support for cultural transformation of cultural public service. It is also difficult to become a qualified digital strategic partner. Measures should be taken to help rural businesses and other organizations complete cultural transformation as soon as possible to meet the needs of the development of the cultural era [19]. The core idea of helping should be "promoting the west from the east," "leading the countryside with the city," and "supporting the weak with the strong." The central committee of China is also promoting the reform of relevant fields at the policy level. However, to implement the "user center," it is necessary to further strengthen the relevant system design and force the residents of grass-roots cultural communities to put "what the people want and what the people need" first, instead of dealing with the superior culture and satisfying the leaders of their own departments as the criteria for their behavior choices [20].

2.2. Edge Algorithm of Cultural Community Service. Each edge node provides information to the cloud platform, including the task information to be completed, computing resources and their network communication. According to the amount of computing tasks, the computing capacity of each node, and the transmission frequency of the channel, the cloud platform optimizes the task allocation decision by comprehensively considering the delay and computing power consumption; in the framework of residential information management, spare edge node $y$ is added.

$$
Y(x)=\frac{1}{N h} \sum_{i=1}^{N} k\left(\frac{X_{i}-x}{h}\right),
$$

where $x$ is the number of nodes of residents. Under the base station cloud platform of a residential area, there are $n$ ECNs, $m$ AECNs, and 1 cloud platform for the energy management calculation task at a certain stage, with different parameters for task generation and processing [21]. In addition, for information transmission, the terminal device $n$ and the standby edge node $m$ are transmitted in the wired LAN, and the power is

$$
W_{t}=\tanh \left(w_{c} x_{t}+u_{c}\left(m_{t} \Theta n_{t-1}\right)+b_{c}\right),
$$

and the data receiving and transmitting between the cloud platform and the cloud platform are wireless, and the power $P$ is

$$
P(x)=\frac{1}{\sqrt{2 \pi}} \exp \left(-\frac{x^{2}}{2}\right) .
$$

The task unloading process is divided into two stages. The first stage determines whether the second ECN will unload the calculation task to AECN for calculation and, if it needs to unload, which AECN should be unloaded to. In the second stage, it is judged whether AECN should continue to unload computing tasks to the cloud [22]. Finally, the unloading choice of each terminal $n$ in the comprehensive decision set does not change, reaching Nash equilibrium and completing the optimal unloading decision.

$$
N t=\frac{\sqrt{1 / n \sum_{i=1}^{n}\left(\mathrm{AECN}_{i t}-\mathrm{AECN}_{i t}\right)^{2}}}{\mathrm{AECN}_{i t}} .
$$

Two decision factors, task delay and energy consumption, are used to build calculation models for local computing, offloading to standby edge computing nodes and further offloading to the cloud.

$$
h_{t}=z_{t} \Theta h_{t-1}+\left(1-z_{t}\right) \Theta h_{t} .
$$

When the terminal decides to execute all the computing tasks locally in ECN, it only involves the local CPU to execute the computing tasks. The local computing model mainly considers the computing delay and energy consumption. The expressions of execution time, computing energy consumption, comprehensive delay, and comprehensive energy consumption are as follows:

$$
W_{\mathrm{ECN}}=-\frac{1}{T} \ln (1+\beta(\mathrm{CPU})) \text {. }
$$

According to the different emphasis of each terminal device on the two factors of delay and energy consumption, the corresponding weight sum is allocated to get the overall load of the computing task when it is executed locally

$$
\ln \left(\frac{R_{i t}}{R_{i t}-1}\right)=\alpha+\sum_{i=1}^{n_{j}} \sum_{r=1}^{n_{j}}\left|y_{j i}-y_{j r}\right|_{i}+\mathfrak{J}_{t} .
$$

When the computing model of edge computing node decides that the terminal will unload the computing task to AECN for execution, the amount of data transmitted by the channel between the nth terminal and its standby edge computing node is $\mathrm{m}$, the transmission power is $R(n, m)$, and the corresponding unloading delay is

$$
\ln (\beta(\mathrm{CPU}))=\alpha+\beta \ln R_{i t}-1+\phi X_{i t}-1+v_{i}+\tau_{t} .
$$

There is also a certain amount of energy consumption in the unloading task:

$$
W-G j j=\frac{1 / 2 u_{j} \sum_{i=1}^{n_{j}} \sum_{r=1}^{n_{j}}\left|y_{j i}-y_{j r}\right|}{n_{j}^{2}} .
$$

If the computing power of the standby edge computing node $m$ to which the task is assigned is $m_{\mathrm{j}}$, then the execution time of the task is

$$
T_{n b}=\sum_{j=2}^{k} \sum_{h=1}^{j-1} G_{j h}\left(m_{j} s_{h}+m_{h} s_{j}\right) D_{j h},
$$

where

$$
\mathrm{C}_{j h}=\int_{0}^{\infty} \mathrm{d} F_{j}(y) \int_{0}^{y}(y-x) \mathrm{d} F_{h}(x),
$$

where $C$ is a constant. When the computing resources of the standby edge computing node are sufficient, it exists when 
the computing resources are insufficient, and this value will be included in the time consumption calculation of the computing tasks in AECN, which further affects the decision-making results of the optimal unloading [23]. The energy consumption of computing task is

$$
C w=\sum_{j=1}^{k} G_{j j} p_{j} s_{j} .
$$

Time and energy consumption can be expressed as

$$
\begin{aligned}
T_{j h} & =\frac{\sum_{Z=1}^{h_{j}} \sum_{r=1}^{n_{h}}\left|y_{j i}-y_{h r}\right|}{n_{j} n_{h}\left(u_{j}+u_{h}\right)}, \\
W & =P T .
\end{aligned}
$$

Because of the particularity of the computing type, the information data is updated every $1 \mathrm{~h}$. If it is not calculated locally, all the data must be transmitted to the standby edge node or cloud, and then the load characteristics are analyzed. Therefore, when calculating the time delay and energy consumption, the three stages must be added up, and finally the comprehensive time delay and energy consumption from the unloading task to the standby edge computing node are obtained

$$
\begin{aligned}
Y_{i t}= & \beta_{0}+\beta_{1} \mathrm{NAF}_{i t}+\beta_{2} \mathrm{TAF}_{i t}+\beta_{3}(\mathrm{AECN})_{i t}+\beta_{4}(\mathrm{DTAF})_{i t} \\
& +\beta_{5} \mathrm{AECN}_{i t}+\beta_{6} \mathrm{PI}_{i t}+\beta_{7} \mathrm{RM}_{i t}+\beta_{8} \mathrm{AECN}_{i t}+\varepsilon_{i t} .
\end{aligned}
$$

The model is the same as unloading to the standby edge node. In the second stage of the decision, if you choose to unload the computing tasks to the cloud server for computing, the delay of task upload, processing, and result return is

$$
R(c)=\frac{d_{j h}-P_{j h}}{d_{j h}+P_{j h}},
$$

where $R(c)$ is the information transmission power between the standby edge node and the cloud platform. At the industrial level, there are "promising culture" and "efficient market" theories based on structural economics, which put forward the theoretical framework of industrial sustainable development [24]. From the regional or group dimension, this paper analyzes that, in the case of multiple poverty risks, the poor areas and households in western China should set the scale of cultural services for rural revitalization according to the coupling coordination state of "human land industry finance" and build a linkage, inclusive and sustainable integration path. To sum up, there are many discussions and fruitful results on the logical relationship, convergence focus, and convergence mechanism between cultural services and rural revitalization in academic circles. However, most scholars explain the two convergences from the partial dimensions rather than from the overall and systematic dimensions. In addition, scholars primarily study two cohesive logics from a common level, such as subject coherence and the combination of mechanisms. However, from the perspective of the individuality of cultural services, there is little research on the mechanisms and realization pathways between the main body and tools of poverty alleviation and rural revitalization. Therefore, it is necessary to promote the quality upgrading from five aspects on the basis of existing cultural service achievements, which can consolidate the existing poverty alleviation achievements and promote rural revitalization. However, at present, there are low-level poverty alleviation, policy poverty alleviation, even digital poverty alleviation, and task poverty alleviation in some poverty-stricken areas. Moreover, due to the dynamic and complex nature of poverty itself, there is a high probability of returning to poverty. In particular, the rural poverty in western China is faced with multiple risks, such as fragile ecological environment, education and healthcare, market competition, poverty culture, and so on. In terms of industrial convergence, industry is the key to the sustainability of cultural services. However, the short-sightedness and administration of industrial poverty alleviation and the longterm and marketization of rural revitalization are in the dilemma of convergence. For example, most of the current industrial poverty alleviation is using administrative forces to promote the convergence of poor households and modern agriculture and using strong intervention to ensure that poor households participate in the distribution of industrial chain benefits; most of the projects are short, flat, and fast, and the phenomenon of homogenization is serious. Therefore, to consolidate the achievements of cultural services through rural revitalization, it is particularly necessary to enhance the endogenous development capacity of the industry and establish a long-term industrial mechanism for stable poverty alleviation through the development of modern agriculture, improving the quality of development, extending the industrial chain, and promoting the integration of the three industries, so as to promote the industry from extensive quantitative growth to quality-effective growth. At the same time, through the development of social enterprises, we can weaken the elite capture and invisible deprivation in the development of enterprises and large households, embody "space justice" in the process of industrial revitalization, and promote the "local" people to share economic value-added benefits. As far as the connection of culture and talents is concerned, the self-development ability of the newly lifted out poverty areas, the newly lifted out poverty population, and the poverty-stricken "marginal households" group is weak, and the vulnerability is prominent, which is very easy to return to poverty.

\section{Experimental Design}

3.1. Research Methods. This paper uses edge algorithm to build mobile information system, combined with rural cultural service elements, to carry out information construction for the people's needs of tourism, information, and belief culture in the development of rural China. In this paper, with the county or township service projects as the research content and 200 residents of a community as the research object, using the way of questionnaire to survey the respondents, online questionnaire feedback results received 
186 , the effective rate of $93 \%$. This paper investigates the project support of mobile information system for rural cultural services and the satisfaction degree of residents' demand for various cultural resources.

3.2. Experimental Design. Because the terminal devices participating in the residential information management are in the same decision-making environment, their unloading decisions affect each other. In order to achieve the global optimal decision-making, under the proposed task unloading principle, the optimal decision-making result is obtained through two-stage unloading process; no user can reduce the computing load of their cultural services by changing their decision results. In order to achieve the Nash equilibrium, a limited number of iterations can be used, combining communication information transmission mode and Nash equilibrium condition. In each time slice, terminal devices update the unloading decision under the basic principle of unloading optimization until the end of the cycle to get the final optimal unloading decision set. A small number of examples are used to analyze and verify. 50 terminals, 5 standby edge computing nodes, and 1 cloud platform are selected. According to the amount of computing tasks, the computing power of each terminal device and standby edge computing node, and the transmission frequency of each channel, and considering the delay and computing power, the task allocation is optimized to achieve Nash equilibrium, assuming that the computing power of five AECNs is the same, and the data transmission channel conditions of each ECN and AECN are the same, and the 50 ECNs are divided into four types with different computing power and have different emphasis on delay and energy consumption. In the computer industry, for the parameter selection of different types of app, according to the existing 1 -year photovoltaic power generation in a residential area, the data record processing file of home noninvasive detection equipment, and the order data of an electric vehicle charging station in a certain area, the information is updated, calculated, and stored in 1-hour cycle. There are many intelligent devices and large amount of data in the home energy management system, so the amount of data and calculation is the largest. The calculation task of electric vehicle charging pile and energy storage equipment is small, so the corresponding parameter setting is small.

\section{Results and Discussion}

4.1. Rural Cultural Service System Based on Mobile Information System. As shown in Figure 1, 86.67\% of the residents surveyed said "no" when they were asked "whether there is a special person or department responsible for supervising/managing the cultural strategy of your organization." When asked whether your organization can quickly and effectively coordinate and communicate with other relevant organizations, share resources, coordinate to provide services, or solve problems for residents when providing public services for residents, only $7.26 \%$ of the residents in the surveyed community said "absolutely able," and 69.35\% of the residents in the surveyed community said "basically able."

As shown in Figure 2, the fourth important dimension of the impact of insufficient effective supply of cultural service resources on organizational cultural maturity is the adequacy of organizational cultural resources. The life of technology lies in the practical application, and the "dragon killing technique" is not helpful to solve the problem of complex national governance. The application of information technology in the field of public service is no exception. Only by effectively linking technology with the needs of citizens and enterprises can we realize the vision of the transformation of public service culture. Even in the world, paying too much attention to information and communication technology solutions and ignoring the resource needs of citizens is the key reason why the early construction of e-culture encountered "Waterloo" in many countries.

As shown in Figure 3, in the modern information society, information has become an important strategic resource and an important source of productivity. However, only when information resources fully meet customer needs, provide accurate and effective supply, and share time and space, cultural service resources truly generate productivity and achieve the expected high efficiency. You can demonstrate it. This also requires all levels of culture to actively collect information resources scattered in all corners of society and make them public and timely open their own data resources.

As shown in Table 1, one of the key factors affecting the effectiveness of the current rural cultural public service is that the cultural service platform is a mere formality, and the key reason is the lack of cultural service resources and links. Combined with the current "one network unified management" mode vigorously implemented by the central government, we can further legislate and clearly require rural culture and local agencies at all levels to link resources and information to the centralized network platform and integrate them into the overall governance network, so as to implement "unified link" and "unified service process." Externally, it helps to reduce the search cost and use cost of service demanders. Internally, it is also conducive to improving the service efficiency of culture and its agencies.

As shown in Table 2, the digital gap between urban and rural areas in China is still prominent, especially the poor digital awareness and digital information utilization ability of farmers, which is another major obstacle to the transformation of rural public service culture. When the respondents were asked "do you often surf the Internet (for example, watch news with computer or mobile phone, use wechat and other activities)", only $19.73 \%$ of them said "often" surf the Internet. The reasons are complex, and the most important one is the low digital literacy caused by the low education level of rural residents. Even with the heads of rural households who are the mainstay of the family economy, only $1.9 \%$ have received college education or above, and $36.7 \%$ still fail to complete the nine-year compulsory education.

As shown in Table 3, most of the existing rural cultural public services are mere formality, and the supply of effective 


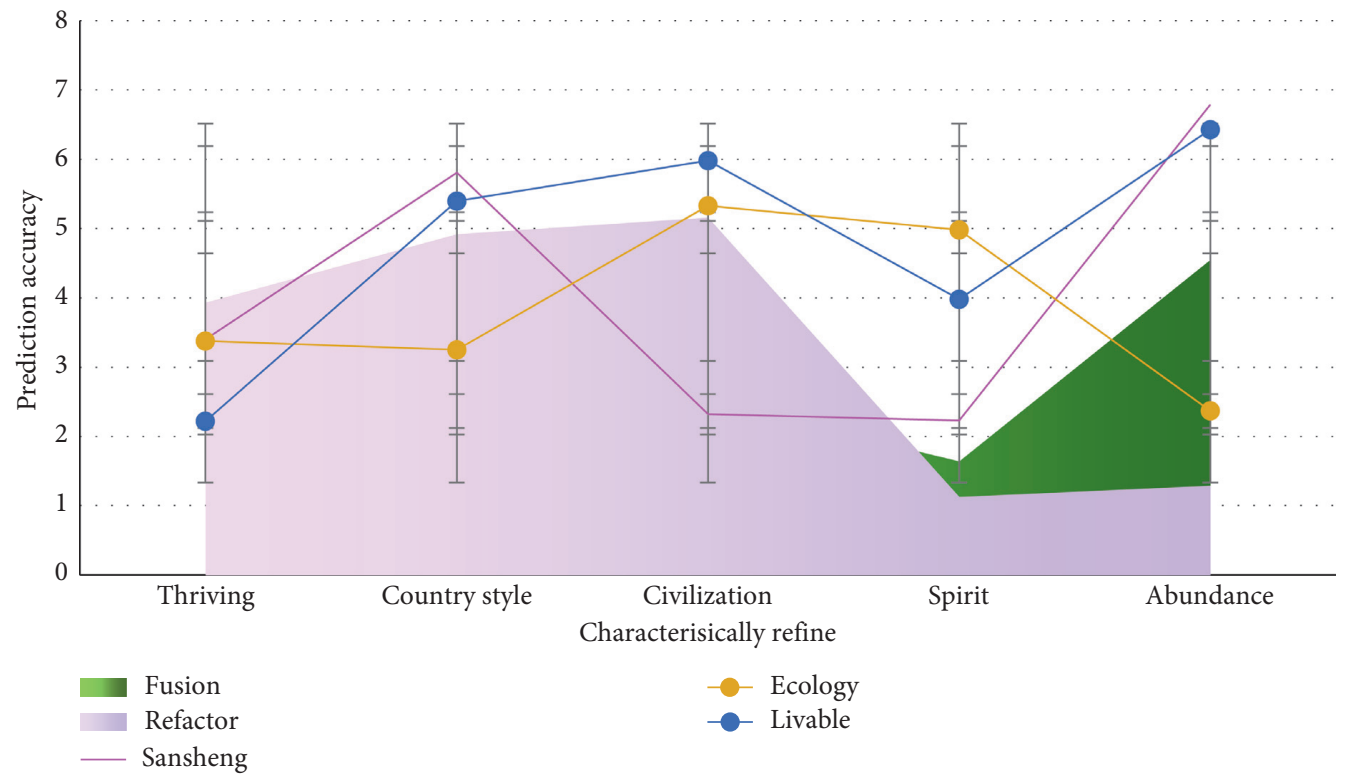

FIGURE 1: Institutions to coordinate communication and share resources.
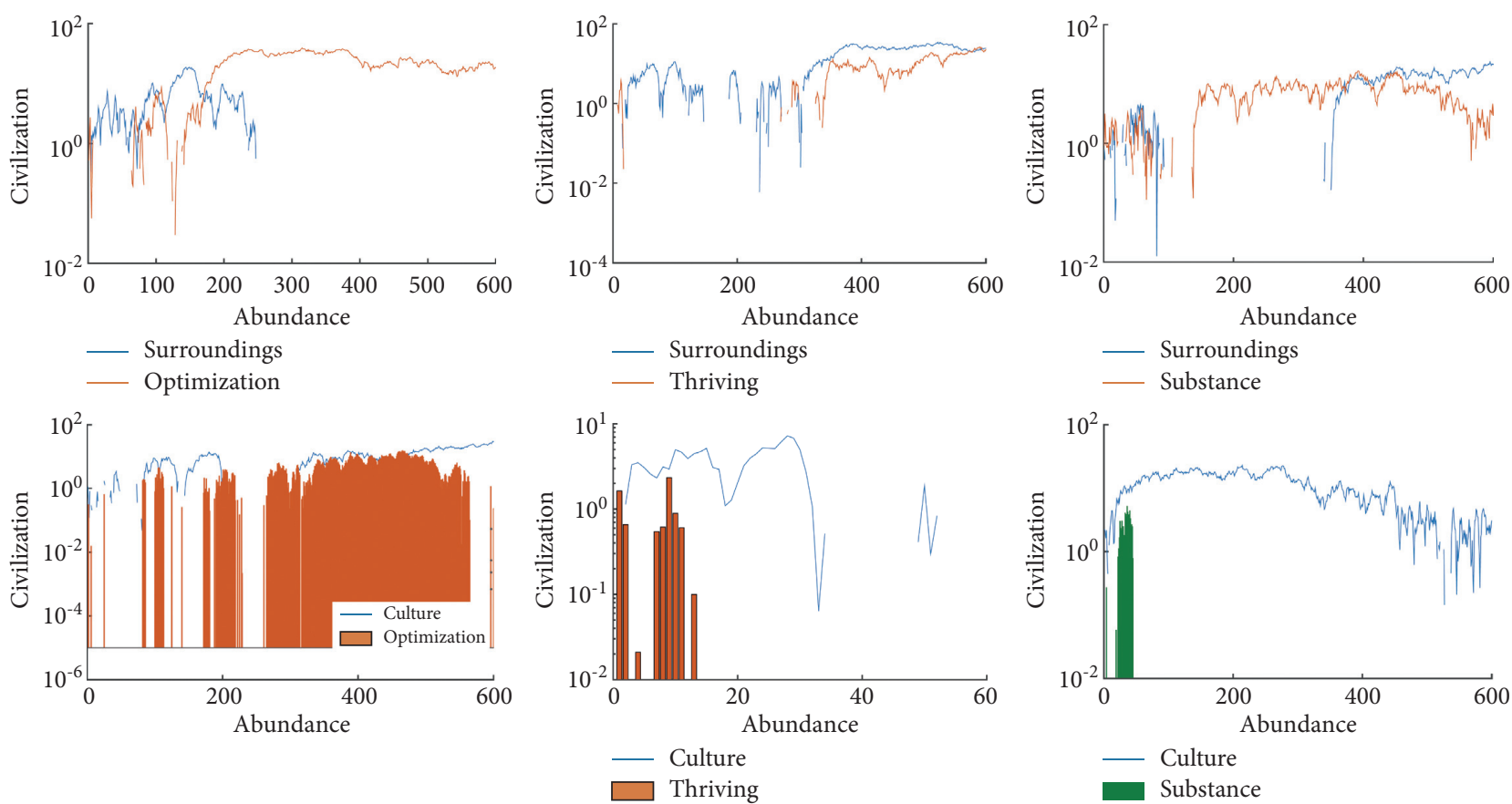

FIGURE 2: Logic relations of rural revitalization governance objectives based on supply and demand.

cultural information resources is seriously insufficient. In particular, the existing content and standards of cultural public services are mostly set up with reference to the needs of urban residents, enterprises, and institutions. In this survey, when the residents of the surveyed communities were asked whether the unfavorable factor that may affect the transformation of organizational culture, such as "serious bureaucratic habits of cultural institutions, lack of pragmatic and cooperative culture," existed in their own institutions, as high as $85.92 \%$ of the residents of the surveyed communities expressed "complete agreement" or "comparative agreement." The severity of bureaucratic malady in rural cultural institutions can be seen.

As shown in Figure 4, when the respondents were asked "do you think the culture online (Network) service platform can meet their own needs for cultural service business," about $52.99 \%$ of the respondents said "most of the time cannot" or "completely cannot," about $43.9 \%$ of the respondents said "most of the time can," and only 14 people said "completely can," accounting for about $3.1 \%$ of the total respondents. At the same time, as high as $79.05 \%$ of the residents surveyed said that "the lack of online cultural 


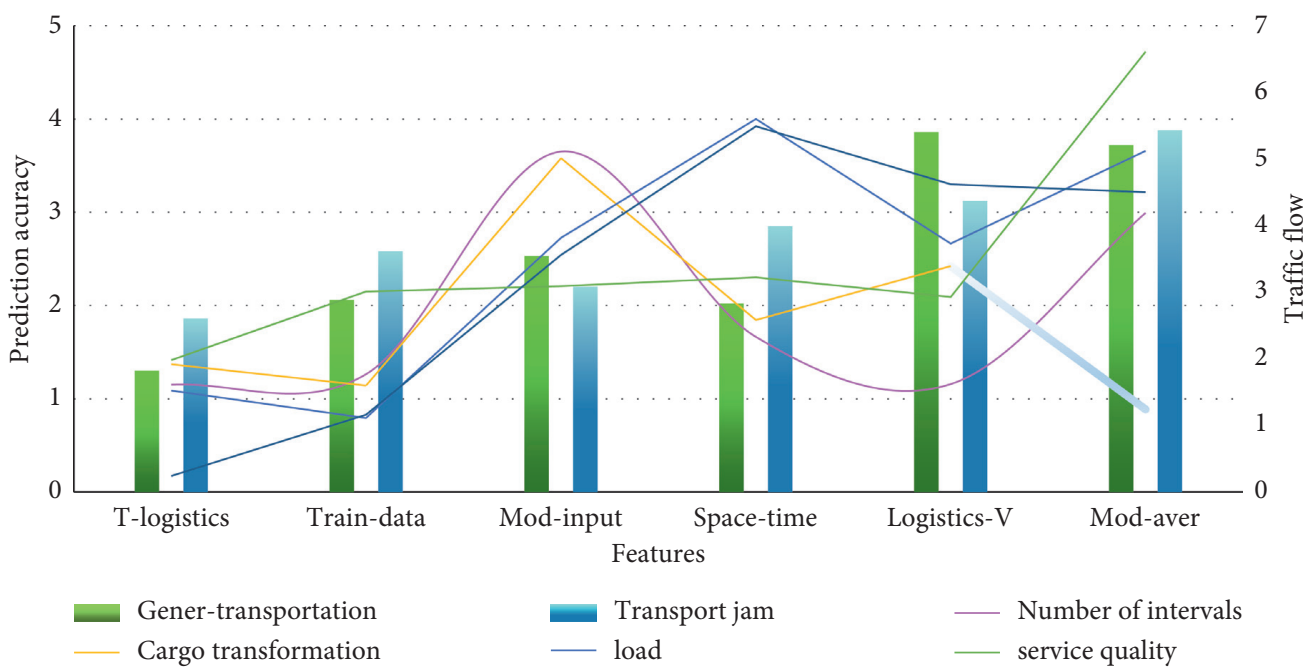

Figure 3: Online cultural service platform business.

TABLE 1: Cultural service resources and link requirements.

\begin{tabular}{lccccc}
\hline Item & Fusion & Sansheng & Refactor & Ecology & Livable \\
\hline Thriving & 3.83 & 3.4 & 3.93 & 3.38 & 2.22 \\
Country style & 4.38 & 5.81 & 4.92 & 5.16 & 5.33 \\
Civilization & 2.51 & 2.32 & 1.13 & 4.98 & 5.98 \\
Spirit & 1.64 & 2.23 & 1.29 & 3.98 \\
Abundance & 4.55 & 6.79 & 6.37 & 6.43 \\
\hline
\end{tabular}

TABLE 2: Digital awareness and digital information utilization ability.

\begin{tabular}{lcccccc}
\hline Item & Culture & Service & Culture & Revival & Cultural tourism & Fusion \\
\hline Substance & 1.68 & 1.92 & 2.97 & 1.35 & 3.85 & 3.62 \\
Rich & 3.66 & 4.94 & 2.84 & 4.6 & 5.73 & 2.01 \\
Industry & 2.09 & 4.47 & 3.55 & 3.18 & 2.67 & 5.33 \\
Thriving & 1.4 & 1.35 & 1.01 & 5.8 & 5.35 & 5.55 \\
Country style & 2.25 & 6 & 2.08 & 5.87 & 4.68 \\
Civilization & 2.93 & 5.57 & & & 2.09 \\
\hline
\end{tabular}

Table 3: Demands of urban residents and enterprises, institutions, and cultural units.

\begin{tabular}{|c|c|c|c|c|c|c|}
\hline Item & Cultural tourism & Fusion & Sansheng & Refactor & Ecology & Livable \\
\hline Civilization & 0.7 & 1.19 & 1.54 & 0.21 & 1.49 & 0.77 \\
\hline Spirit & 3.84 & 1.75 & 2.15 & 1.91 & 3.8 & 2.32 \\
\hline Abundance & 3.42 & 5.9 & 2.23 & 4.79 & 2.65 & 4.03 \\
\hline Surroundings & 4.34 & 2.03 & 1.4 & 5.67 & 2.29 & 5.46 \\
\hline Optimization & 2.05 & 1.63 & 2.55 & 3.12 & 3.89 & 4.9 \\
\hline Culture & 5.18 & 2.27 & 1.53 & 5.44 & 5.75 & 5.17 \\
\hline
\end{tabular}

service resources suitable for the rural situation on the integrated cultural service platform" is the key factor affecting the cultural transformation construction of rural public service supply.

As shown in Figure 5, in addition to the cultural maturity level of public service providers, whether people can enjoy the dividends brought by the cultural era ultimately depends on the awareness and ability of cultural service utilization on the demand side, that is, the digital literacy of human individuals. Skilled workers serve robots and machines, and skilled workers use robots and machines to create extraordinary services. This also means that enjoying the future cultural and social development dividend is based on people's digital literacy, and people with insufficient digital literacy will become tools of cultural technology.

As shown in Figure 6, to promote the generation of vision and strategy of cultural transformation through policy guidance, the cultural transformation of public service needs cultural institutions to have a clear vision and strategy of cultural 


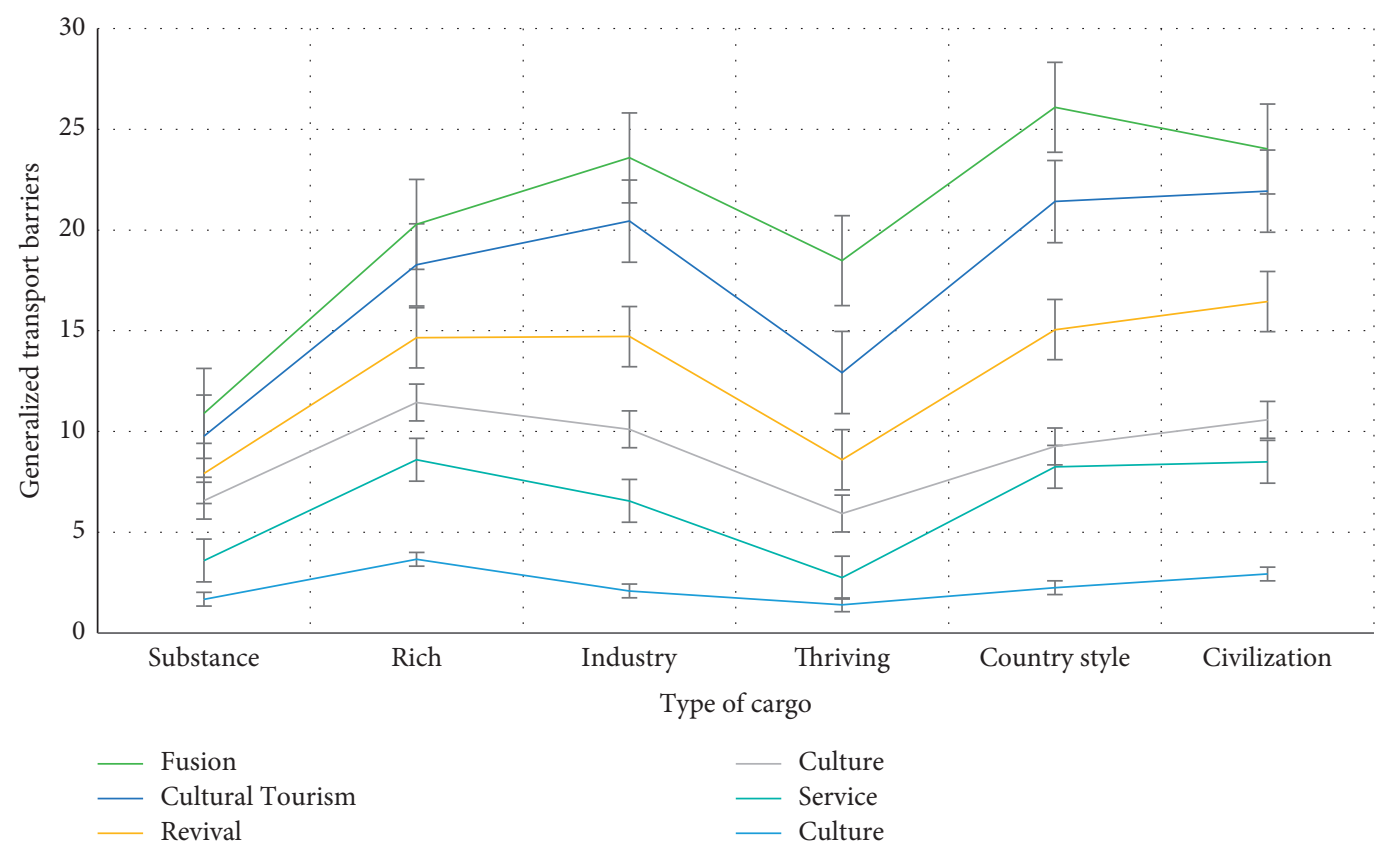

FIgUre 4: The needs of cultural service business.

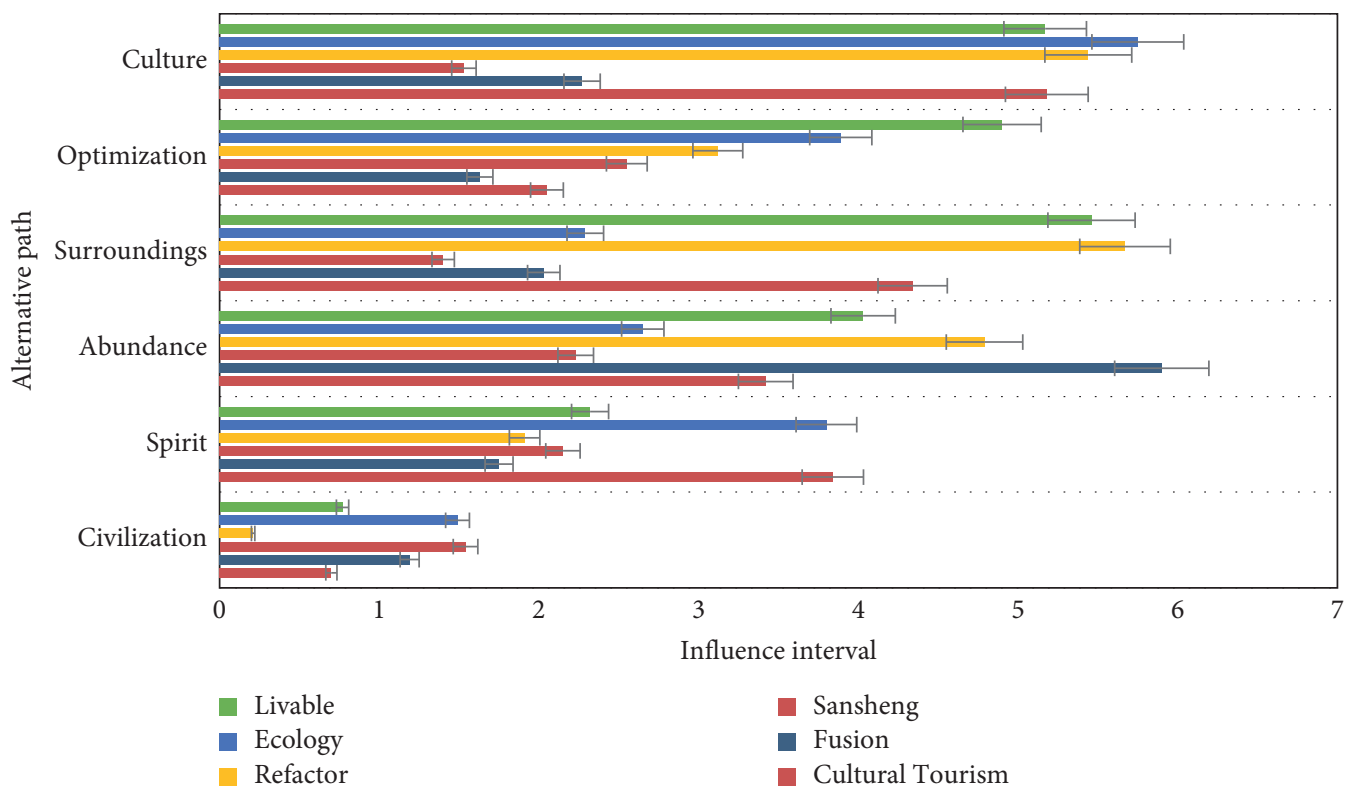

FIGURE 5: Robots and machines create extraordinary services.

transformation. This not only requires the leaders of cultural institutions to have the ability to formulate and realize the strategic vision, but also needs the corresponding high-level policy support. Under China's centralized system, it is a feasible way to guide rural cultural institutions to form the vision and strategy of cultural public service transformation by strengthening the "top-level design," introducing policies by the superior culture or directly by the central culture, clarifying and strengthening the responsibility of rural cultural leadership to promote the cultural transformation of public service.
As shown in Table 4, 3.9\% of household heads have not attended school, and $32.8 \%$ of household heads have only received primary education. As the main force of the long-term residents in rural areas left-behind women and the elderly in rural areas have lower levels of education and are typical digitally poor groups. Left-behind women with only primary education and illiteracy accounted for $45.6 \%$ and $9.5 \%$, respectively. Left-behind elders in rural areas have a lower level of education, and the proportion of Chinese illiteracy reached $45.6 \%$, and $42.6 \%$ of them 


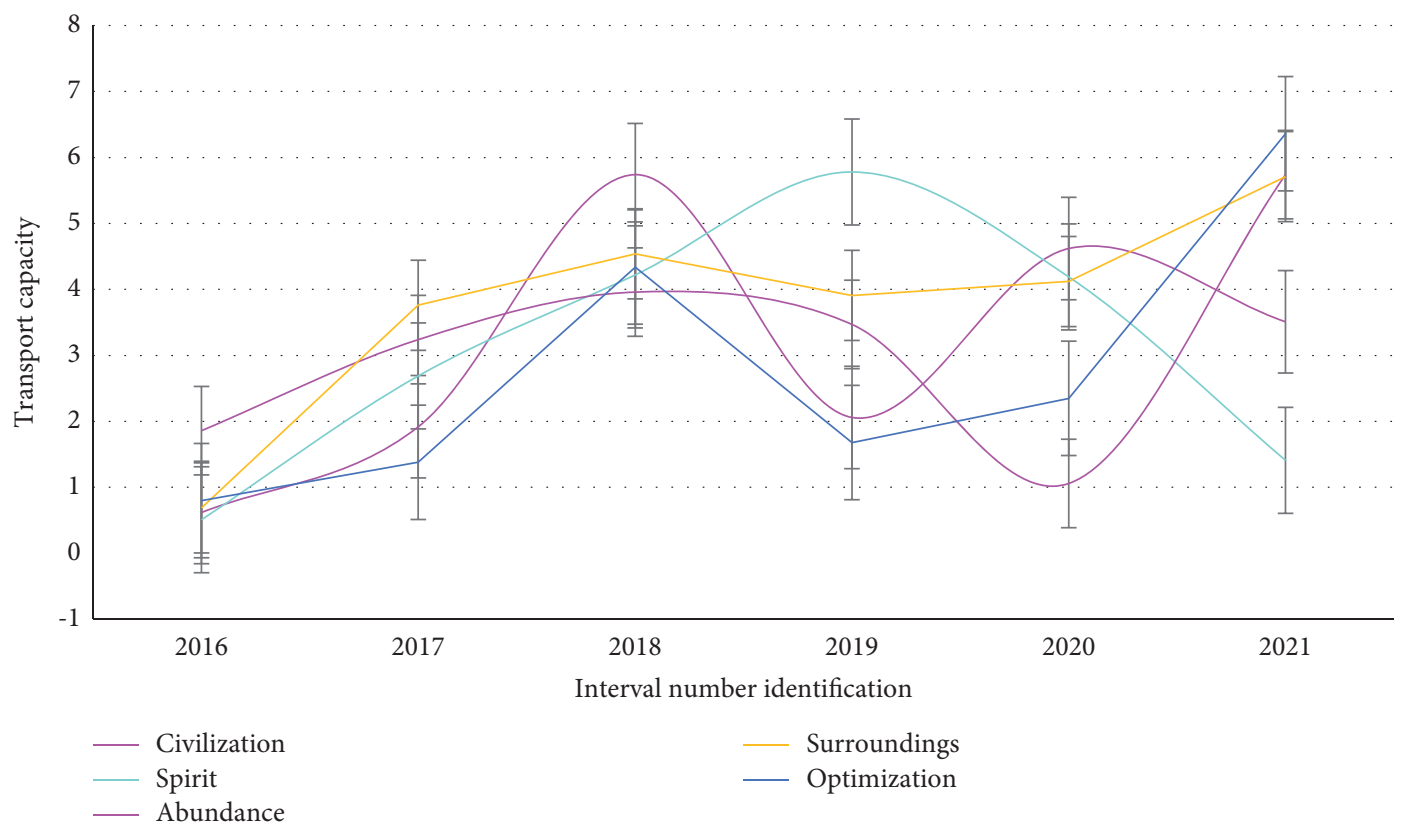

FIgURE 6: Village cultural leaders promote the transformation of public service culture.

TABLE 4: Village cultural digital poverty group.

\begin{tabular}{|c|c|c|c|c|c|c|}
\hline Item & Ecology & Refactor & Ecology & Culture & Revival & Cultural tourism \\
\hline Civilization & 1.2 & 1.6 & 1.39 & 0.64 & 1.5 & 1.66 \\
\hline Spirit & 1.25 & 3.28 & 1.06 & 2.29 & 2.59 & 1.75 \\
\hline Abundance & 4.17 & 3.05 & 2.46 & 2.3 & 4.05 & 3.26 \\
\hline Surroundings & 3.55 & 1.48 & 1.81 & 1.28 & 3.09 & 2.93 \\
\hline Optimization & 3.41 & 3.21 & 2.12 & 2.93 & 2.07 & 4.63 \\
\hline Culture & 2.57 & 1.03 & 5.67 & 1.03 & 1.22 & 4.12 \\
\hline
\end{tabular}

have a primary education level, which greatly affected their awareness and ability to use digital information.

As shown in Table 5, from 2016 to 2021, due to the constraints of time and cost, it may be difficult for professional service personnel to carry out precise guidance of "no details." As a temporary volunteer service, it is difficult for college students to win the trust of villagers. Community party members, community volunteers, and their children are acquaintances in rural society, so they are more likely to win the trust of the villagers, so they are easier to intervene in education and publicity. Of course, in the context of large rural population mobility, we can also reduce the adverse effects by allowing the children of migrant workers in business to handle for the elderly in rural production and life.

As shown in Figure 7, to establish and improve the microlevel policy of rural revitalization, local culture needs to plan rural revitalization according to the local reality and characteristics and form specific policy programs. Based on existing policies, it is necessary to deepen and integrate the institutional supply of poverty alleviation and revitalization, develop detailed rules and implementation plans for the convergence of both, and improve regional policies for convergence. Finally, to achieve the overall planning of fund policy, through the establishment of the agricultural fund coordination platform, the agricultural funds used for different purposes should be integrated, managed, and used in a unified way, so as to improve the efficiency of fund use and avoid the phenomenon of repeated expenditure or insufficient expenditure.

As shown in Figure 8, in this survey, when the residents of the surveyed community were asked about the recognition of the statement that "the level of cultural construction of businesses and other organizations outside culture is low," about $91.2 \%$ of the respondents said "fully agree" or "relatively agree." From the supply side of public service, the cultural transformation of public service needs to form a pragmatic and cooperative organizational culture within the culture and then form a collaborative governance model to provide citizens with holistic and seamless services. However, the bureaucratic problems in the underdeveloped areas of central and western China are more prominent, which hinder the transformation process of cultural public services.

As shown in Figure 9, residents in the central and western regions are in a relatively closed environment, more conservative in concept, and lacking enterprising and innovative spirit. In this survey, when the respondents were asked "do you think the online cultural service 
TABle 5: Rural culture and population mobility.

\begin{tabular}{lccccc}
\hline Years & Civilization & Spirit & Abundance & Surroundings & Optimization \\
\hline 2016 & 0.62 & 0.51 & 1.86 & 0.69 & 3.76 \\
2017 & 1.92 & 2.69 & 3.24 & 4.54 & 1.38 \\
2018 & 5.74 & 4.22 & 3.96 & 3.91 & 4.34 \\
2019 & 2.06 & 5.78 & 3.47 & 4.12 & 1.68 \\
2020 & 4.62 & 4.19 & 1.06 & 5.71 & 2.35 \\
2021 & 3.51 & 1.41 & 5.74 & 6.36 \\
\hline
\end{tabular}

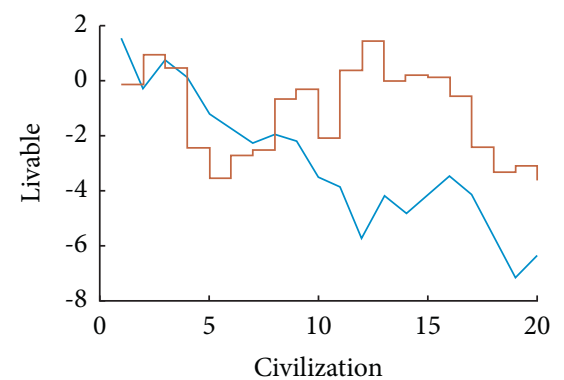

Cultural Service and Industrial Construction
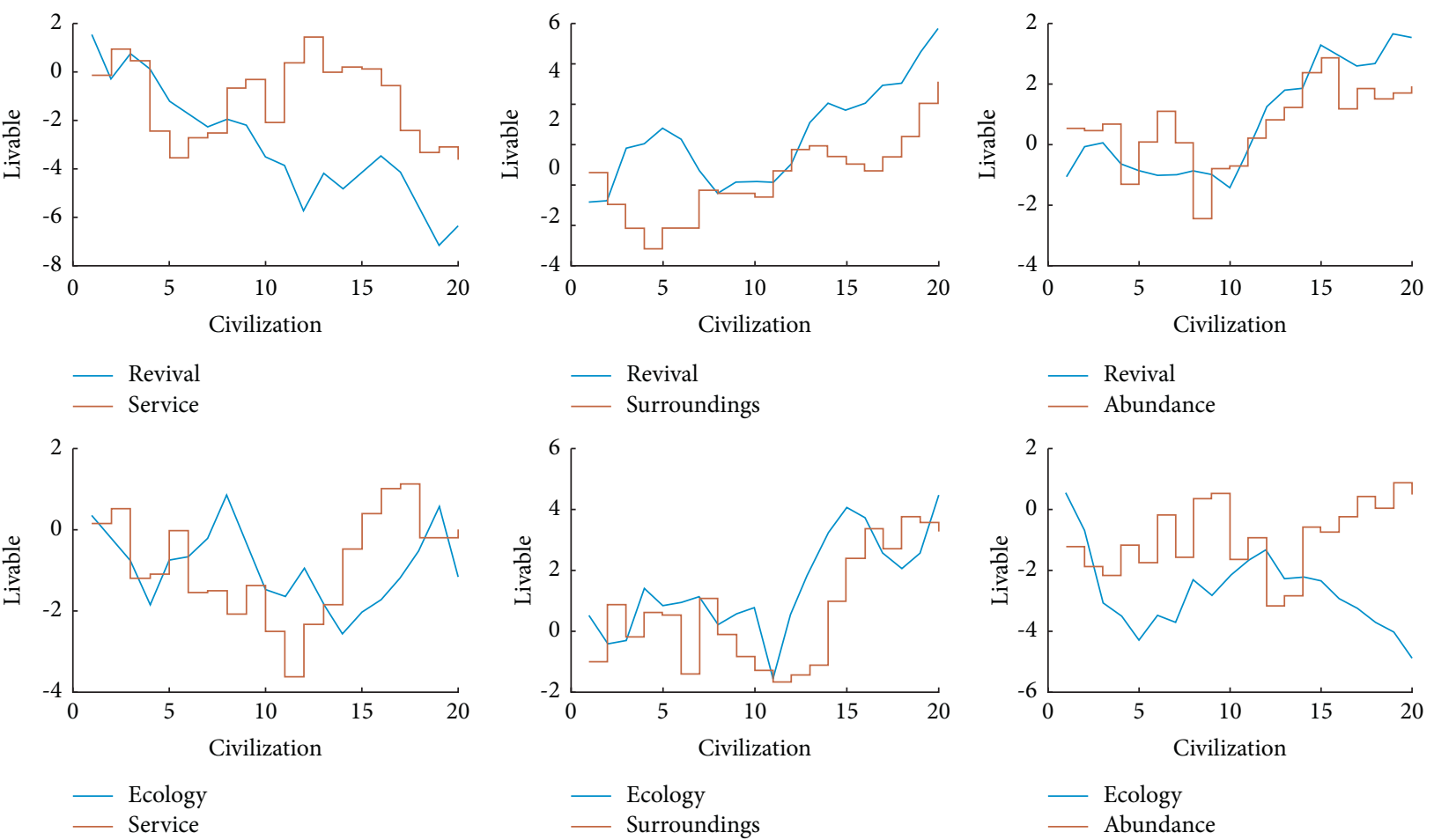

Figure 7: Cultural service and industrial construction.

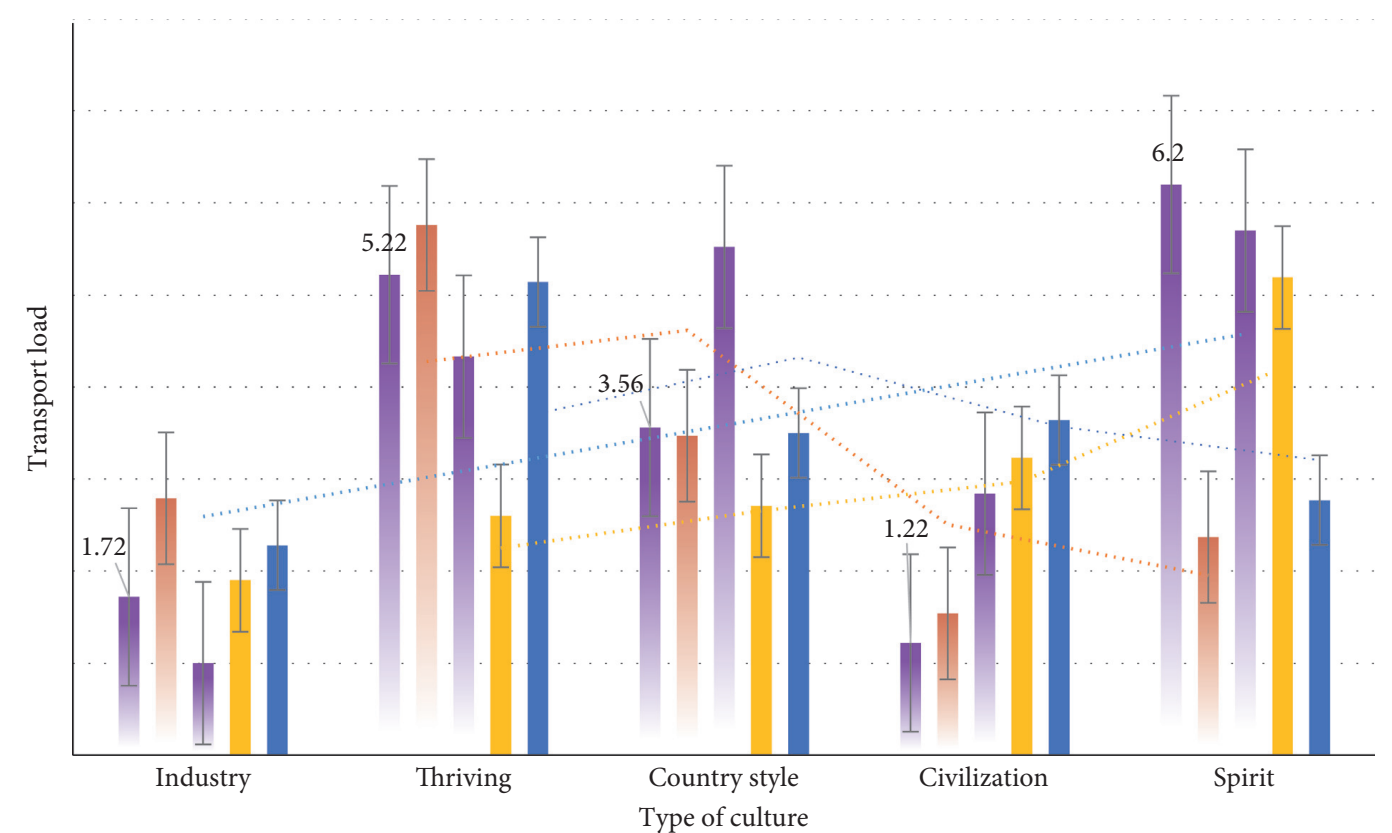

FIgURE 8: The organizational culture of public service culture transformation. 


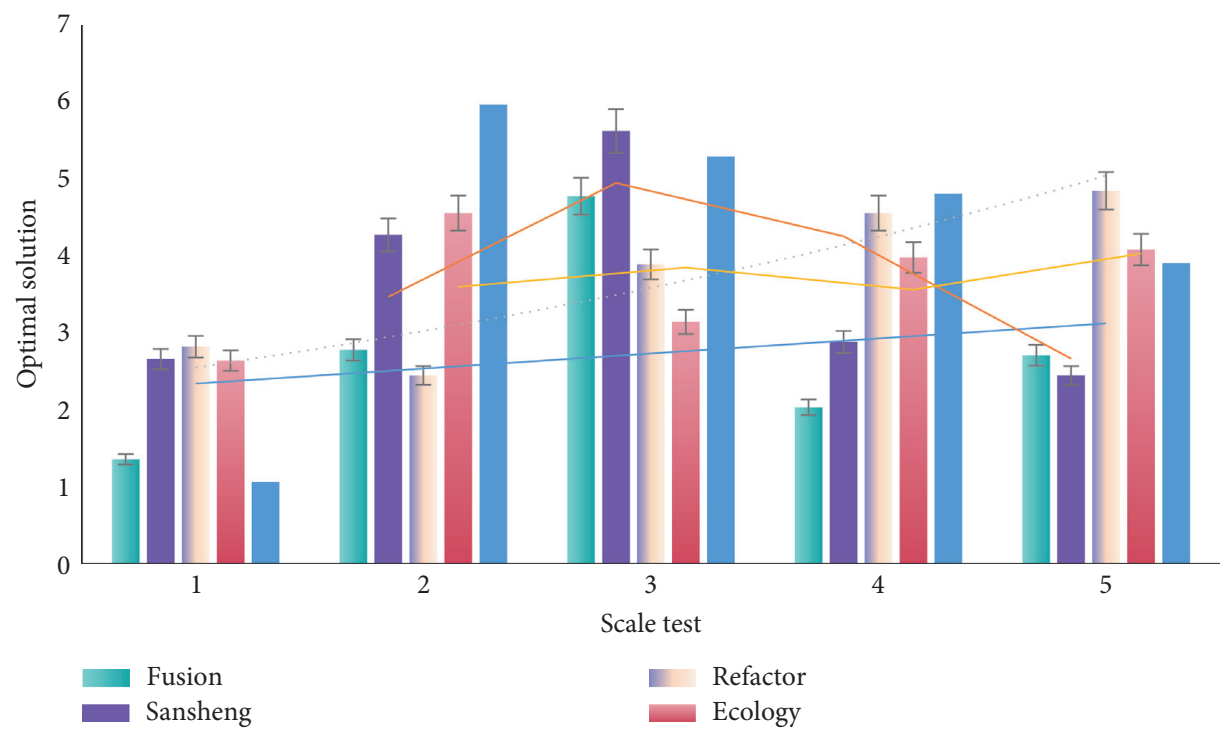

FIgURE 9: Online cultural service platform business.
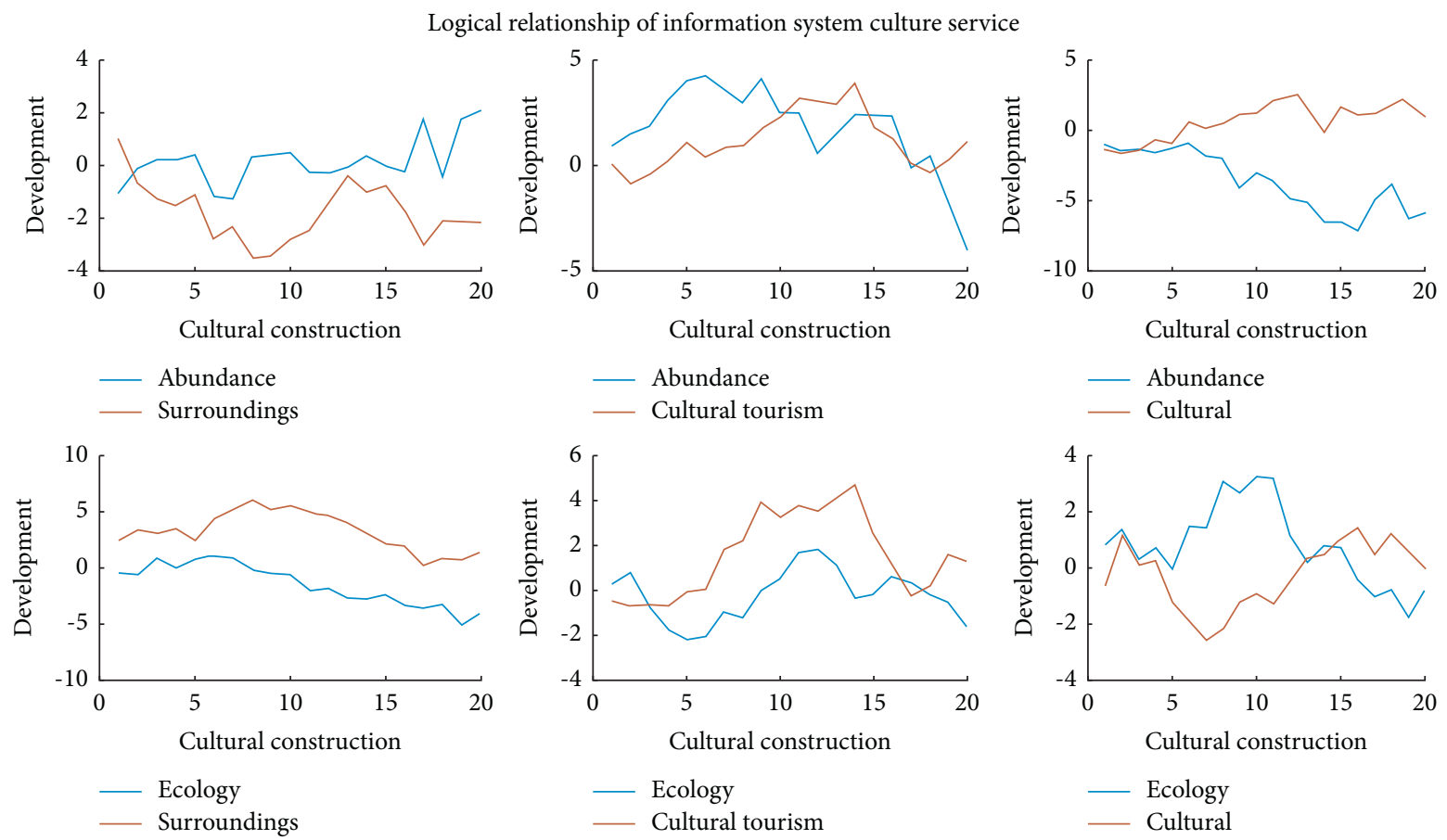

FIGURE 10: Logical relationship of information system culture service.

platform can meet their own needs for cultural service business," 148 residents who have used the online cultural service platform for business think that the online cultural service platform is "all-round" or "in most cases" can meet their own business needs as high as $69 \%$, while $82.35 \%$ of the 28 residents who have not used the online service platform feel that the cultural online service platform "cannot" or "cannot" meet their own business needs in most cases.

As shown in Figure 10,65.53\% of people believe that the cultural service system can reduce the people's dependence on special cultural services, thereby obtaining resources from a diversified information service system. $35.63 \%$ of people said that the cultural service system can improve the efficiency of community offline cultural services by more than $50 \%$. The rest said that the rural cultural service system "basically" meets their daily needs. Therefore, whether it is from the cultural service level or the information system level, the current rural cultural service model and service process need to be constructed from the height of the cultural service supply system reform. 
4.2. Discussion. Integrating community education and family backfeeding education helps villagers improve their digital literacy and form an open mind. From a fundamental point of view, whether it is some rural residents with low digital literacy or conservative concepts, it is difficult to accept cultural public services as new things, and its most important consequence is that all rural residents lack the "autonomous citizenship ability." In the context of the digital age, the key to improving rural residents' "autonomous citizenship" is to integrate family backfeeding education to promote a full range of digital literacy education centered on community education.

Intelligent cultural service is the use of artificial intelligence methods to realize the transition from "informatization, network center" to "intelligence, knowledge center" and assist commanders in solving the perception, understanding, and cognition problems in the command field. The system architecture and technical architecture of the command information system will change. The system implements corresponding intelligent technology applications around functional domains such as situation, command, control, and support to enhance the cognition and decisionmaking efficiency of combat command.

In order to avoid the deviation of vision and strategy, the top-level policy design also needs to clarify the legal status of collective decision-making and consultation democracy in the development of cultural transformation vision and strategy of rural cultural institutions to ensure that the rural culture strengthens consultation and communication and strives to form within the culture the consensus and recognition of the vision of cultural transformation, because only the cultural transformation strategy that forms an identity within the culture can be better implemented in cultural practice. Specifically, policy design is mainly carried out from two levels: one is the detailed strategic plan for the development of rural public service culture formulated and promulgated by the state council to clarify cultural responsibilities and macrotransformation strategies at all levels; the other is to refer to the practices of advanced provinces. State-level culture leads the development of statelevel local public service cultural change strategic plans and then encourages lower-level cultural sectors to introduce specific policies and measures, the next generation of local public service cultural change.

\section{Conclusions}

The construction of rural civilization and culture is not only an overall lifestyle that contains rich contents such as material production, knowledge creation, spiritual sublimation, and value pursuit, but also a mirror that illuminates the overall state of civilization and progress of human society. The revitalization of rural culture in the post-well-off era is the revitalization of rural culture combining "rebuilding space with culture" and "building culture with space." Culture not only changes people's spiritual outlook with invisible power, but also drives the development of industry with tangible power. The cultural service mainly develops the cultural industry through "cultural people" and "cultural education" and through the excavation of local cultural traditions and customs. Based on the concept of shared development, the collective economy will be developed and expanded, and new collective economic organizations and rural cooperatives will be established through organizational restructuring to promote the organic connection between small farmers and modern agriculture. Connect two separate cultural services through certain devices and methods. These devices can be tools such as planning, policies, and institutional mechanisms. They are the "media" and "bridges" for consolidating the results of cultural services and rural revitalization. Specifically, it is necessary to link up tools from the aspects of project planning, policy formulation, fund coordination, and assessment, so as to construct a cultural service system from multiple levels.

\section{Data Availability}

No data were used to support this study.

\section{Conflicts of Interest}

The authors declare that they have no conflicts of interest.

\section{Acknowledgments}

This work was supported by Ministry of Education of Humanities and Social Science Project (authorization no. 18YJC760065).

\section{References}

[1] D. Wang, X. Chen, J. Zhang et al., "Geographic information system-based health risk assessment of rural drinking water in Central China: a case study of You County, Hunan," Environmental Monitoring and Assessment, vol. 193, no. 2, pp. 1-13, 2021.

[2] M. Kiec, C. D’Agostino, and S. Pazdan, "Impact on road safety and operation of rerouting traffic in rural travel time information system," Sensors (Basel, Switzerland), vol. 20, no. 15, pp. 41-45, 2020.

[3] O. V. Remneva, E. G. Ershova, and I. V. Molchanova, "The development of organization of three-level system of obstetrics service in the region using information technologies," Health Care of the Russian Federation, vol. 62, no. 4, pp. 181-186, 2019.

[4] T. Lin, H. Yu, Q. Wang et al., "Surface water quality assessment based on the integrated water quality Index in the Maozhou river basin, Guangdong, China," Environmental Earth Sciences, vol. 80, no. 10, pp. 1-16, 2021.

[5] S. Manzur, N. A. Mustaffa, M. M. Habib et al., "Change management for information system in public service," Research, vol. 6, no. 8, pp. 45-51, 2020.

[6] S. K. Sharma, B. Metri, Y. K. Dwivedi et al., "Challenges common service centers (CSCs) face in delivering e-government services in rural India," Government Information Quarterly, vol. 9, no. 4, pp. 101-103, 2021.

[7] V. Livinus, M. F. A. Adhikara, and R. Kusumapradja, "Hospital management information system usefulness in the health services industry at Indonesia: mandatory or voluntary?" Jurnal Medicoeticolegal Dan Manajemen Rumah Sakit, vol. 10, no. 1, pp. 61-63, 2021. 
[8] N. Sun and Y. Peng, "Study on strategies of optimizing service contact for new rural waste classification system," in Proceedings of the 3rd International Conference on Energy Resources and Sustainable Development (ICERSD 2020), vol. 236, no. 18, Article ID 03001, Harbin, China, December 2021.

[9] T. Liu, Z. Gao, and H. Guan, "Educational information system optimization for artificial intelligence teaching strategies," Complexity, vol. 2021, no. 3, pp. 1-13, 2021.

[10] S. S. Gill, I. Chana, and R. Buyya, "Agri-info: cloud based autonomic system for delivering agriculture as a service," Internet of Things, vol. 9, no. 2, Article ID 100131, 2020.

[11] J. Carter, E. Vasquez, and A. Jones, "Spatial analysis of livestock grazing and forest service management in the high uintas wilderness, Utah," Journal of Geographic Information System, vol. 12, no. 2, pp. 45-69, 2020.

[12] S. Oh and N. Park, "A model for improving information protection service cost estimates: focused on public institutions in Korea," Journal of Computational and Theoretical Nanoscience, vol. 17, no. 7, pp. 3250-3255, 2020.

[13] C. Gao, G. R. Zhao, J. H. Lu et al., "Decentralised movinghorizon state estimation for a class of networked spatialnavigation systems with random parametric uncertainties and communication link failures," IET Control Theory \& Applications, vol. 9, no. 18, pp. 2666-2677, 2019.

[14] S. S. Mohamed, A.-F. I. Abdel-fatah, and M. A. Mohamed, "Performance evaluation of MANET routing protocols based on QoS and energy parameters," International Journal of Electrical and Computer Engineering (IJECE), vol. 10, no. 4, pp. 3635-3642, 2020.

[15] Y. Zhang, L. Sun, H. Song et al., "Ubiquitous WSN for healthcare: recent advances and future prospects," IEEE Internet Things, vol. 1, no. 4, pp. 311-318, 2019.

[16] "Systems engineering and electronics 11 maintenance algorithm based on LEACH-DCHS protocol in WSN," Computer Engineering and Application, vol. 45, no. 30, pp. 95-97, 2019.

[17] G. Rahimeh and M. L. Ali, "Improving LEACH protocol using SFLA algorithm to reduce the energy consumption of wireless sensor networks," International Journal of Scientific Engineering and Technology, vol. 6, no. 7, pp. 255-259, 2017.

[18] K. B. Payal and K. Krishna, "A clustering algorithm with reduced cluster head variations in LEACH protocol," Control and Communications, vol. 7, no. 4, pp. 321-336, 2016.

[19] E. Siow, T. Tiropanis, and W. Hall, "Analytics for the Internet of things,” ACM Computing Surveys, vol. 51, no. 4, pp. 1-36, 2018.

[20] S. Kims and D. S. Eom, "Distributed transmission power control for network programming in wireless sensor networks," Wireless Personal Communications, vol. 72, no. 2, pp. 1533-1548, 2019.

[21] N. T. Dinh, T. Gu, and Y. Kim, "Rendezvous cost-aware opportunistic routing in heterogeneous duty-cycled wireless sensor network systems," IEEE Access, vol. 7, no. 3, pp. 59-69, 2019.

[22] P. Yuan, T. Zhang, N. Yang, H. Xu, and Q. Zhang, "Energy efficient network localisation using hybrid TOA/AOA measurements," IET Communications, vol. 13, no. 8, pp. 963-971, 2019.

[23] S. Sun, X. Z. Wang, M. Bill et al., "A hidden semi-Markov model for indoor radio source localization using received signal strength," Signal Processing, vol. 166, no. 8, pp. 132-142, 2020.

[24] Y. J. Hu, B. Wu, P. Chen et al., "Design and verification of attitude and heading measurement system for small tail sitting aircraft," Systems Engineering and Electronics, vol. 39, no. 4, pp. 866-875, 2017. 